\title{
Service quality in Iranian hospitals: A systematic review and meta-analysis
}

\author{
Satar Rezaei ${ }^{1}$, Mohammad Hajizadeh ${ }^{2}$, Hamed Zandian ${ }^{3}$, Afshin Fathi $^{4}$, Bijan Nouri ${ }^{5}$ \\ Received: 17 Oct 2017 \\ Published: 11 Jul 2018
}

\begin{abstract}
Background: This study aimed to explore service quality in Iranian hospitals by a systematic review and meta-analysis of the existing literature.

Methods: The literature search in the international (PubMed, Scopus, and the ISI) and Iranian (SID, Iranmedex, and Magiran) scientific databases was conducted to identify studies (published in English and Persian) used the service quality gap (SERVQUAL) model to examine service quality in Iranian hospitals between 2000 and 2016. The databases were searched using a combination of the following keywords: "hospital service quality", or "healthcare service quality", and "SERVQUAL model", or "gap model", and "Iran". A random-effects meta-analysis model was used to investigate the quality of hospital care in Iran.

Results: A total of 13 articles with 4,217 patients were included in the study. Results indicate that there are negative gap values between patients' expectations and perceptions in six SERVQUAL dimensions namely. tangibility, reliability, responsiveness, assurance, empathy, and access. The overall mean score of patients' expectations and perceptions of quality of hospital care in Iran were estimated 4.59 and 3.69, respectively (i.e., quality score gap $=-0.9$ ). The highest and lowest quality score gap values were related to the reliability and responsiveness dimensions, correspondingly.

Conclusion: The study found that expectations of patients from hospital care have not been met in Iran. Thus, improving service quality in Iranian hospitals warrants further attention by health professionals, health policy-makers, and hospital managers.
\end{abstract}

Keywords: Service quality, Iranian hospitals, SERVQUAL model, Systematic review, Meta-analysis

Copyright $@$ Iran University of Medical Sciences

Cite this article as: Rezaei S, Hajizadeh M, Zandian H, Fathi A, Nouri B. Service quality in Iranian hospitals: A systematic review and meta-analysis. Med J Islam Repub Iran. 2018 (11 Jul);32:59. https://doi.org/10.14196/mjiri.32.59

\section{Introduction}

The provision of high-quality care is the main goal of all healthcare systems worldwide. Service quality in the health sector is more important compared to that of other sectors because high-quality health services have a significant impact on health and well-being of individuals. In fact, healthcare quality has been the subject of considerable interest because improving the quality of care has a

\section{Corresponding author: Dr Bijan Nouri, bijannuri@gmail.com}

${ }^{1 .}$ Research Center for Environmental Determinants of Health, Kermanshah University of Medical Sciences, Kermanshah, Iran.

2. School of Health Administration, Faculty of Health, Dalhousie University, Halifax, Canada.

3. Social Determinants of Health Research Center, Ardabil University of Medical Sciences, Ardabil, Iran.

4. Department of Pediatrics, Ardabil University of Medical Sciences, Ardabil, Iran.

5. Social Determinants of Health Research Center, Research Institute for Health

Development, Kurdistan University of Medical Sciences, Sanandaj, Iran. positive impact on the health status of a country's population, which, in turn, benefits the economy and society as a whole. Improving the quality of hospital care is an important priority in all countries, especially in developing countries where hospitals are the main healthcare providers.

Measurement of service quality is the first step for qual-

\section{$\uparrow$ What is "already known" in this topic:}

Improving the quality of inpatient care is an important priority in all countries, especially in developing countries where hospitals are the main healthcare providers. To date, several studies have been conducted to measure the quality of services in hospitals in various regions in Iran.

\section{$\rightarrow$ What this article adds:}

The study found that expectations of patients from hospital care have not been met in Iran. Future researchers should be conducted about main determinants of satisfaction of patients with considering dimension such as discharge management, decreasing in waiting time and processes of delivery's hospital care in the hospital setting in the country. 
ity improvement and management in health care systems; thus, the quality assessment in hospital care is the focus of increasing interest (1-4). In other words, it is essential to measure and monitor the quality of hospital services to ensure that patients' needs are satisfied and there is enough improvement in the quality of inpatient care over time $(3,5,6)$. The measurement of service quality in hospitals also enables hospital managers to identify areas that require further attention in terms of quality improvement (7).

Providing healthcare services for patients according to their needs and expectations is essentials for survival and success of the organization in the competitive environment of the healthcare market (15). This implies that meeting patients' expectations and their needs can be used as an indicator in monitoring the quality of services in healthcare organizations such as hospitals. In others word, the difference between patients' perceptions and their expectations about hospital services can be defined as the gap in the quality of services $(4,5)$ : the lower the difference, the higher the quality. To reduce the quality gap, it is critical to recognize patients' expectations and their perceptions and, therefore, determine the strength and weakness of hospital services to implement effective strategies to improve the quality of service provided in hospitals.

One of the most commonly used multi-dimensional instruments to assess the quality of services from patients' or consumers' perspective is the service quality gap (SERVQUAL) model. This model measures the gap in service quality from six dimensions namely. tangibles, responsiveness, reliability, empathy, assurance, and access. This model, which suggested by Parasuraman et al. (1988) (17), is a valid tool to measure the quality of services across different sectors including commercial or industrial businesses, non-profit, and government-owned organizations such as hospitals (7, 9-14).

Several studies used the SERQUAL model to measure the quality of services in hospitals in different regions of Iran. The results of these studies are heterogeneous. For example, a study conducted in Kashan reported the highest and lowest means of quality score for empathy $(3.97 \pm 0.75)$ and tangibility $(3.76 \pm 0.58)$ dimensions, respectively (16). While another study in Kermanshah indicated that the highest and lowest quality gaps were associated with the assurance (-0.88) and responsiveness (0.56) dimensions, respectively (4). A study by Abolghasem Gorji reported the highest and the lowest gaps in the access (-2.55) and assurance (-0.697) dimensions, respectively, in Tehran (10). Thus, it seems necessary to systematically review the current studies to have a better understanding of service quality in Iranian hospitals as a whole. This study aimed to fill this gap in the literature and investigate the quality of healthcare services provided by Iranian hospitals. Specifically, for the first time, this study systematically reviews the existing data in the literature to determine the quality of hospital services in Iran. The results of this study help us to understand the quality of hospital care in Iran, and it may ultimately leads to a greater awareness among health professionals and health policy-makers of the quality gap in hospital care services in Iran.

\section{Methods}

\section{Search strategy}

Six international and Iranian bibliographic databases (PubMed, Scopus, the Institute for Scientific Information [ISI], Scientific Information Database [SID], Iranmedex, and Magiran) were searched by two authors independently to identify studies that used the SERVQUAL model to examine service quality in Iranian hospitals. Since the first study used the SERVQUAL model to examine service quality in Iranian hospitals was published in the year 2000, the search was limited to original studies published in Persian or English over the period between January 2000 and December 2016. To find the relevant studies, a combination of the following Persian and English keywords was used: "hospital service quality", or "healthcare service quality", and "SERVQUAL model", or "gap model" and "Iran". The reference lists of the retrieved articles were also reviewed manually to identify further relevant studies.

\section{SERVQUAL Model}

The SERVQUAL model, developed by Parasuraman et al. in 1988 (17), has five dimensions including tangibles (4 questions), reliability (5 questions), responsiveness (4 questions), assurance (4 questions), and empathy (5 questions). A new dimension of "access" (two questions) was added as the sixth dimension in some studies. Based on this model, service quality in the hospital was defined by the differences between the scores of patients' perceptions and their expectations about healthcare services provided by hospitals (i.e., service quality $[\mathrm{SQ}]=$ score of perceptions [P] - score of expectations [E]). In other words, the quality gap in each service quality dimensions and its subitems were computed by subtracting perception (what is) score from expectation (what should be) score. If patients' perceptions and their expectations of hospital services were equal, the quality gap equal zero. If patients' perceptions score of hospital services was less (more) than patients' expectations score, the quality gap considered negative (positive) $(17,18)$.

\section{Study selection}

The following inclusion criteria were applied to select studies that measured service quality in Iranian hospitals: 1) studies that reported the mean and standard deviation (SD) of overall expectation and perception scores of total quality and their dimensions; 2) studies were published in Persian or English; 3) studies conducted in hospitals; 4) studies that used the SERVQUAL model to examine the quality of hospital care; 4) studies with available full text; and 5) studies that examined quality of hospital care from patient's perspective. The following studies were excluded from the analysis: review articles, qualitative studies, brief reports, letters to the editor, editorial comments, working papers, and studies with duplicated data (i.e., if two studies published in Persian and English with similar results, the Persian study was excluded from the review). Based 
Table 1. Checklist for assessing the quality of primary studies

\begin{tabular}{lll}
\hline No & Questions & Score \\
1. & Are the research questions clearly stated? \\
2. & Is the approach appropriate for the research question? \\
3. & Is the study context clearly described? \\
4. & Is the role of the researcher clearly described? \\
5. & Is the sampling method clearly described? \\
6. & Is the sampling strategy appropriate for the research question? \\
7. & Is the data collection method clearly described? \\
8. & Is the data collection method appropriate to answer the research question? \\
9. & Is the method of analysis clearly described? \\
10. & Are the main characteristics of the population well described? \\
11. & Is the analysis appropriate for the research question? \\
12. & Are the claims made supported by sufficient evidence? \\
\hline Note: The checklist questions were obtained from Moosazadeh et al. 2014.
\end{tabular}

on the inclusion and exclusion criteria, two authors independently reviewed all articles and any disagreement was resolved by discussion or consultation with a third author, if required.

\section{Data extraction}

A self-constructed checklist was used to extract the required information from each article. The following in- formation was collected from the articles: the first author of the paper, year of publication, study location, the language of published article, type and number of hospitals included in the study, the overall quality scores and its dimensions. A checklist (Table 1) that has been used in previous studies (19-21) used as a tool to evaluate the quality of the articles. The checklist included 12 questions about the aim of the study, research questions, study me-

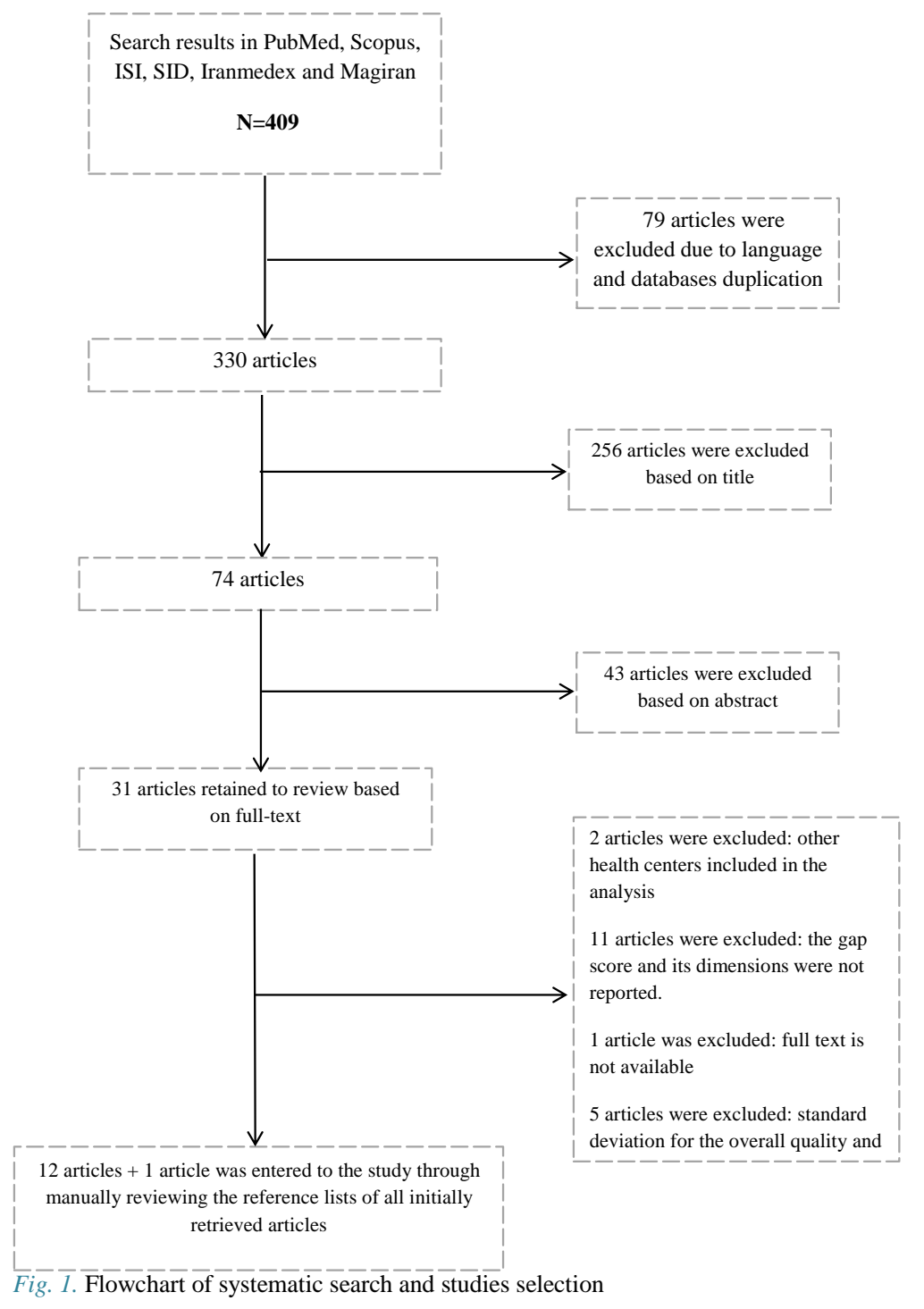


thod, sample size, sampling method, data collection tool, status of variables evaluation, target population and method of the analysis. One point was assigned if a study met the quality requirement for each question, and zero was assigned otherwise. The quality scores for the studies was calculated by summing all the points. Similar to previous studies (19-21), a quality score of at least 8 was required for the studies to be retained in the review.

\section{Statistical analysis}

The Chi-squared based Q-test, I-squared and Tausquared statistics were used to examine the heterogeneity among studies included in the review. A random-effects meta-analysis model was used to estimate the pooled overall mean score of patients' perceptions and expectations of the quality of hospital care in Iran. Point estimation of the overall mean scores of patients' perceptions and expectations were estimated by a forest plot with $95 \%$ confidence interval $(95 \% \mathrm{CI})$. The Egger's test was used to evaluate publication bias. The data analysis was performed using Stata statistical software (Version 12; Stata Corporation, College Station, TX, USA).

\section{Results}

The results of the systematic review process are presented in Fig. 1. In total, 409 articles were found in the initial search. As reported in Fig. 1, 79 articles were excluded due to language and databases duplication. In addition, 256 articles were excluded based on the title and 43 articles were excluded based on the abstract review. If the abstract did not explicitly state that the "SERVQUAL model" or "gap model" was used to measure service quality in hospitals, it excluded from the study. Two articles were excluded because other health centers were included in the analysis. This yielded 30 articles with available fulltext. Moreover, 16 studies were not included in the analysis because these papers did not report the means or standard deviations of the quality gaps for the six SERV-
QUAL dimensions, required in the meta-analysis analysis. This resulted in 12 qualified articles. In addition, one eligible article was identified through manually reviewing the reference lists of all initially retrieved articles. Based on the inclusion and exclusion criteria, 13 articles $(n=4217$ patients) were included in the review $(4,11,13,22-31)$, and they obtained the quality score of greater than 8 .

The characteristics of the 13 articles included in the systematic review are reported in Table 2. The overall sample was evenly distributed by sex (1877 female vs. 1899 male). Thirty-nine percent $(n=5)$ of the articles were published from 2011 to 2013 and the remaining 61\% $(n=8)$ published over the period between 2014 and 2016. Most articles $(n=9,69.2 \%)$ were published in Persian. The overall number of hospitals included in all studies was 36 hospitals but in one study the number was not clear. .Moreover, eight studies were conducted in university hospitals, two in military hospitals and one in private hospitals. The ownership status of hospitals was not mentioned in one study.

The review of the selected studies indicated a wide variation in patients' expectations among the studies. While the overall patients' expectations in a study by Hekmat Pou et al. (24) in Shiraz was 4.93 ( $\mathrm{SD}=0.22$ ), this figure was $3.62(\mathrm{SD}=0.47)$ in a study by Bahmei et al. (25) in Arak. There was also variation in the overall patients' perceptions about hospital care across the studies. The highest and lowest score of patients' perceptions were reported in studies by Ameryoun et al. (22) (3.9, $\mathrm{SD}=0.80)$ conducted in Tehran and Sina et al. (23) (2.69, $\mathrm{SD}=0.26)$ conducted in Sari, respectively. Based on the random-effect model, the pooled average score of patients' expectations and their perceptions from hospital care services provided in Iranian hospitals was estimated to be 4.59 (95\% CI, 4.59-4.78) and 3.69 (95\% CI, 3.154.22), respectively (Figs. 2 and 3). This suggested that patients' expectations exceeded their perceptions about hospital care services in Iran.

\begin{tabular}{|c|c|c|c|c|c|c|c|c|c|c|c|c|}
\hline \multirow{2}{*}{$\begin{array}{l}\text { First author, } \\
\text { publication date }\end{array}$} & \multirow{2}{*}{$\begin{array}{l}\text { Lan- } \\
\text { guage }\end{array}$} & \multirow{2}{*}{$\begin{array}{l}\text { Location of } \\
\text { study }\end{array}$} & \multirow{2}{*}{$\begin{array}{c}\text { Sample } \\
\text { size }\end{array}$} & \multicolumn{2}{|c|}{ Hospitals } & \multicolumn{7}{|c|}{ Overall Quality scores and its dimensions } \\
\hline & & & & Type§ & $\mathrm{N}$ & $\begin{array}{c}\text { Overall } \\
\text { Mean } \pm \mathrm{SD}^{6}\end{array}$ & $\begin{array}{l}\text { Tangibility } \\
\text { Mean } \pm \text { SD }\end{array}$ & $\begin{array}{l}\text { Reliability } \\
\text { Mean } \pm \text { SD }\end{array}$ & $\begin{array}{l}\text { Responsiveness } \\
\text { Mean } \pm S D\end{array}$ & $\begin{array}{l}\text { Assurance } \\
\text { Mean } \pm \text { SD }\end{array}$ & $\begin{array}{c}\text { Empathy } \\
\text { Mean } \pm S D\end{array}$ & $\begin{array}{c}\text { Access } \\
\text { Mean } \pm \text { SD }\end{array}$ \\
\hline $\begin{array}{l}\text { Ajam, } \\
2011\end{array}$ & Persian & Zabol & 100 & - & 1 & $\begin{array}{l}4.49 \pm 0.16 \\
4.50+0.12\end{array}$ & $\begin{array}{l}4.46 \pm 0.29 \\
4.48+0.29\end{array}$ & $\begin{array}{l}4.51 \pm 0.29 \\
4.54+0.25\end{array}$ & $\begin{array}{l}4.45 \pm 0.19 \\
453+0.24\end{array}$ & $4.50 \pm 0.32$ & $4.47 \pm 0.37$ & $4.40 \pm 0.41$ \\
\hline $\begin{array}{l}2011 \\
\text { Zarei, }\end{array}$ & Persian & Tehran & 983 & $\mathrm{PH}$ & 8 & $\begin{array}{l}4.50 \pm 0.12 \\
4.92 \pm 0.20\end{array}$ & $\begin{array}{l}4.48 \pm 0.29 \\
4.95 \pm 0.18\end{array}$ & $\begin{array}{l}4.54 \pm 0.25 \\
4.93 \pm 0.21\end{array}$ & $\begin{array}{l}4.53 \pm 0.24 \\
4.92 \pm 0.24\end{array}$ & $\begin{array}{l}4.48 \pm 0.28 \\
4.94 \pm 0.20\end{array}$ & $\begin{array}{l}4.50 \pm 0.35 \\
4.85 \pm 0.34\end{array}$ & $\begin{array}{c}4.44 \pm 0.52 \\
-\end{array}$ \\
\hline $\begin{array}{l}2011 \\
\text { Razlansari, }\end{array}$ & Persian & Kermanshah & 400 & EH & 5 & $\begin{array}{l}4.02 \pm 0.63 \\
4.57 \pm 0.38 \\
3.67+0.51\end{array}$ & $\begin{array}{l}4.18 \pm 0.62 \\
4.48 \pm 0.43 \\
3.65 \pm 0.57\end{array}$ & $\begin{array}{l}4.05 \pm 0.71 \\
4.53 \pm 0.39 \\
3.44 \pm 0.81\end{array}$ & $\begin{array}{l}4.06 \pm 0.74 \\
4.65 \pm 0.31 \\
3.62 \pm 0.67\end{array}$ & $\begin{array}{l}4.11 \pm 0.69 \\
4.64 \pm 0.29 \\
3.74 \pm 0.82\end{array}$ & $\begin{array}{l}3.78 \pm 0.77 \\
4.55 \pm 0.32 \\
3.89 \pm 0.87\end{array}$ & $\begin{array}{l}- \\
-\end{array}$ \\
\hline Hekmat Pou, & Persian & Arak & 260 & EH & - & $4.93 \pm 0.22$ & $4.96 \pm 0.15$ & $4.97 \pm 0.27$ & $4.94 \pm 0.42$ & $4.96 \pm 0.29$ & $4.94 \pm 0.56$ & $4.82 \pm 0.34$ \\
\hline Ameryoun, & Persian & Tehran & 264 & MH & 3 & $\begin{array}{l}3.60 \pm 0.92 \\
4.59 \pm 0.67\end{array}$ & $\begin{array}{l}3.66 \pm 1.02 \\
4.52 \pm 1.05\end{array}$ & $\begin{array}{l}3.76 \pm 0.96 \\
4.6 \pm 0.72\end{array}$ & $\begin{array}{l}3.65 \pm 1.07 \\
4.56 \pm 0.84\end{array}$ & $\begin{array}{l}3.80 \pm 0.99 \\
4.63 \pm 0.71\end{array}$ & $\begin{array}{l}3.61 \pm 1.07 \\
4.54 \pm 0.81\end{array}$ & $\begin{array}{l}3.11 \pm 1.24 \\
4.53 \pm 0.87\end{array}$ \\
\hline $\begin{array}{l}2013 \\
\text { Sina, }\end{array}$ & Persian & Sari & 331 & EH & 1 & $\begin{array}{c}3.9 \pm 0.80 \\
4.10 \pm 0.28\end{array}$ & $\begin{array}{c}3.83 \pm 0.91 \\
4.0 \pm 0.57\end{array}$ & $\begin{array}{l}3.89 \pm 0.85 \\
3.90 \pm 0.73\end{array}$ & $\begin{array}{l}3.84 \pm 0.94 \\
4.14 \pm 0.74\end{array}$ & $\begin{array}{l}4.07 \pm 0.85 \\
4.17 \pm 0.59\end{array}$ & $\begin{array}{l}3.79 \pm 1.35 \\
4.30 \pm 0.49\end{array}$ & $\begin{array}{c}3.66 \pm 1.13 \\
-\end{array}$ \\
\hline 2014 & & & & & & $2.69 \pm 0.26$ & $2.98 \pm 0.57$ & $1.91 \pm 0.77$ & $2.79 \pm 0.72$ & $2.50 \pm 0.67$ & $3.25 \pm 0.54$ & - \\
\hline $\begin{array}{l}\text { Aghamolaei, } \\
2014\end{array}$ & English & Hormozgan & 100 & EH & 1 & $\begin{array}{l}4.73 \pm 0.34^{\mathrm{A}} \\
3.44 \pm 0.69^{\mathrm{B}}\end{array}$ & $\begin{array}{l}4.73 \pm 0.40 \\
3.42 \pm 0.83\end{array}$ & $\begin{array}{l}4.72 \pm 0.43 \\
3.49 \pm 0.72\end{array}$ & $\begin{array}{l}4.76 \pm 0.38 \\
3.34 \pm 0.81\end{array}$ & $\begin{array}{l}4.76 \pm 0.47 \\
3.56 \pm 0.86\end{array}$ & $\begin{array}{l}4.69 \pm 0.47 \\
3.39 \pm 0.80\end{array}$ & $\begin{array}{l}- \\
-\end{array}$ \\
\hline $\begin{array}{l}\text { Ayoubian, } \\
2015\end{array}$ & Persian & Isfahan & 104 & MH & 1 & $\begin{array}{l}4.64 \pm 0.53 \\
3.86 \pm 0.81\end{array}$ & $\begin{array}{l}4.62 \pm 0.55 \\
3.77 \pm 0.88\end{array}$ & $\begin{array}{l}4.59 \pm 0.66 \\
3.84 \pm 0.89\end{array}$ & $\begin{array}{l}4.62 \pm 0.65 \\
3.80 \pm 0.95\end{array}$ & $\begin{array}{c}4.71 \pm 0.54 \\
4.1 \pm 0.89\end{array}$ & $\begin{array}{c}4.61 \pm 0.58 \\
3.81 \pm 1.0\end{array}$ & $\begin{array}{l}4.69 \pm 0.69 \\
3.50 \pm 1.13\end{array}$ \\
\hline $\begin{array}{l}\text { Gholami, } \\
2016\end{array}$ & Persian & Shiraz & 200 & - & 6 & $\begin{array}{c}4.69 \pm 0.30 \\
4.3 \pm 0.65\end{array}$ & $\begin{array}{c}4.5 \pm 0.41 \\
4.21 \pm 0.55\end{array}$ & $\begin{array}{l}4.81 \pm 0.38 \\
4.21 \pm 0.65\end{array}$ & $\begin{array}{c}4.8 \pm 0.38 \\
4.29 \pm 0.64\end{array}$ & $\begin{array}{l}4.77 \pm 0.37 \\
4.41 \pm 0.58\end{array}$ & $\begin{array}{l}4.61 \pm 0.44 \\
4.39 \pm 0.54\end{array}$ & $\begin{array}{l}4.54 \pm 0.57 \\
4.46 \pm 0.65\end{array}$ \\
\hline Gholami, & English & Shiraz & 100 & EH & 1 & $4.35 \pm 0.62$ & $4.31 \pm 0.62$ & $4.36 \pm 0.61$ & $4.35 \pm 1.02$ & $4.38 \pm 0.61$ & $4.39 \pm 1.2$ & - \\
\hline $\begin{array}{l}2016 \\
\text { Rezaei, }\end{array}$ & English & Kermanshah & 400 & $\mathrm{EH}$ & 7 & $\begin{array}{c}3.295 \pm 0.75 \\
4.58 \pm 0.59\end{array}$ & $\begin{array}{c}3.45 \pm 0.86 \\
4.61 \pm 0.9\end{array}$ & $\begin{array}{l}3.42 \pm 0.86 \\
4.43 \pm 0.80\end{array}$ & $\begin{array}{l}3.27 \pm 0.89 \\
4.52 \pm 0.51\end{array}$ & $\begin{array}{l}3.55 \pm 1.04 \\
4.70 \pm 0.65\end{array}$ & $\begin{array}{c}3.45 \pm 0.8 \\
4.65 \pm 0.34\end{array}$ & - \\
\hline 2016 & & & & & & $3.8 \pm 1.06$ & $3.81 \pm 1.12$ & $3.65 \pm 1.21$ & $3.96 \pm 1.45$ & $3.82 \pm 1.33$ & $3.78 \pm 1.6$ & - \\
\hline Bahmei, & Persian & Shiraz & 582 & EH & 1 & $3.62 \pm 0.47$ & $3.75 \pm 0.64$ & $3.55 \pm 0.62$ & $3.61 \pm 0.71$ & $3.78 \pm 0.57$ & $3.62 \pm 0.72$ & $2.98 \pm 0.80$ \\
\hline $\begin{array}{l}2016 \\
\text { Sadeghdaghighi. }\end{array}$ & English & Rasht & 393 & $\mathrm{EH}$ & 1 & $\begin{array}{c}3.22 \pm 0.51 \\
4.049+0.82\end{array}$ & $\begin{array}{l}3.39 \pm 0.65 \\
3.97 \pm 0.87\end{array}$ & $\begin{array}{l}3.23 \pm 0.65 \\
4.09 \pm 0.86\end{array}$ & $\begin{array}{c}3.3 \pm 0.70 \\
4.06 \pm 0.87\end{array}$ & $\begin{array}{l}3.23 \pm 0.60 \\
4.07 \pm 0.85\end{array}$ & $\begin{array}{l}3.22 \pm 0.62 \\
4.03 \pm 0.83\end{array}$ & $2.56 \pm 0.82$ \\
\hline $\begin{array}{l}\text { Sadeghdaghighi, } \\
2016\end{array}$ & Engisin & Tosin & - & 511 & & $3.75 \pm 0.69$ & $3.66 \pm 0.75$ & $\begin{array}{l}4.09 \pm 0.00 \\
3.87 \pm 0.72\end{array}$ & $3.78 \pm 0.73$ & $3.73 \pm 0.75$ & $3.73 \pm 0.76$ & - \\
\hline
\end{tabular}

Note: All studies were cross-sectional design. SD is standard deviation

$\S \mathrm{EH}=$ Educational Hospital; $\mathrm{PH}=$ Private Hospital, $\mathrm{MH}=$ Military Hospitals

$\mathrm{A}=$ Expectation score

$\mathrm{B}=$ Perception score 


\begin{tabular}{|c|c|c|c|c|}
\hline \multirow[b]{2}{*}{ Author } & \multicolumn{3}{|l|}{ Publication } & \multirow{2}{*}{$\begin{array}{l}\% \\
\text { Weight }\end{array}$} \\
\hline & Year & & ES $(95 \%$ Cl) & \\
\hline Ajam & 2011 & $\Rightarrow$ & $4.49(4.18,4.80)$ & 22.79 \\
\hline Zarei & 2011 & $=$ & $4.92(4.53,5.31)$ & 16.71 \\
\hline Hekmat Pou & 2012 & $=$ & $4.93(4.50,5.36)$ & 14.46 \\
\hline Razlansari & 2012 & $\rightarrow-$ & $4.57(3.83,5.31)$ & 5.70 \\
\hline Ameryoun & 2013 & $\longrightarrow$ & $-4.59(3.28,5.90)$ & 1.95 \\
\hline Aghamolaei & 2014 & $\rightarrow-$ & $4.73(4.06,5.40)$ & 6.96 \\
\hline Sina & 2014 & $\rightarrow$ & $4.10(3.55,4.65)$ & 9.77 \\
\hline Ayoubian & 2015 & $\longrightarrow-$ & $4.64(3.60,5.68)$ & 3.06 \\
\hline Gholami & 2016 & $\rightarrow-$ & $4.69(4.10,5.28)$ & 8.68 \\
\hline Gholami & 2016 & $\rightarrow$ & $4.35(3.13,5.57)$ & 2.27 \\
\hline Rezaei & 2016 & $\longrightarrow$ & $4.58(3.42,5.74)$ & 2.49 \\
\hline Bahmei & 2016 & -- & $3.62(2.70,4.54)$ & 3.84 \\
\hline Sadeghdaghighi & 2016 & $\rightarrow$ & $4.05(2.44,5.66)$ & 1.32 \\
\hline \multicolumn{2}{|c|}{ Overall (I-squared $=12.3 \%, p=0.322)$} & $\diamond$ & $4.59(4.41,4.78)$ & 100.00 \\
\hline NOTE: Weights & om random effects analysis & & & \\
\hline
\end{tabular}

Fig. 2. Forest plot of the overall mean score of patients' expectations from the received hospital services in Iran

\begin{tabular}{|c|c|c|c|}
\hline \multirow[b]{2}{*}{ Author } & \multicolumn{2}{|l|}{ Publication } & \multirow{2}{*}{$\begin{array}{l}\% \\
\text { Weight }\end{array}$} \\
\hline & Year & $\mathrm{ES}(95 \% \mathrm{Cl})$ & \\
\hline Ajam & 2011 & $4.50(4.26,4.74)$ & 12.65 \\
\hline Zarei & 2011 & $4.02(2.79,5.25)$ & 7.69 \\
\hline Hekmat Pou & 2012 & $3.60(1.80,5.40)$ & 5.26 \\
\hline Razlansari & 2012 & $3.67(2.67,4.67)$ & 8.94 \\
\hline Ameryoun & 2013 & $3.90(2.33,5.47)$ & 6.15 \\
\hline Aghamolaei & 2014 & $3.44(2.09,4.79)$ & 7.11 \\
\hline Sina & 2014 & $2.69(2.18,3.20)$ & 11.61 \\
\hline Ayoubian & 2015 & $3.86(2.27,5.45)$ & 6.07 \\
\hline Gholami & 2016 & $4.30(3.03,5.57)$ & 7.49 \\
\hline Gholami & 2016 & $3.30(1.83,4.77)$ & 6.57 \\
\hline Rezaei & 2016 & $3.80(1.72,5.88)$ & 4.40 \\
\hline Bahmei & 2016 & $3.22(2.22,4.22)$ & 8.94 \\
\hline Sadeghdaghighi & 2016 & $3.75(2.40,5.10)$ & 7.11 \\
\hline \multicolumn{2}{|c|}{ Overall (I-squared $=74.5 \%, p=0.000$ ) } & $3.69(3.15,4.22)$ & 100.00 \\
\hline NOTE: Weights & $\mathrm{m}$ random effects analysis & & \\
\hline
\end{tabular}

Fig. 3. Forest plot of the overall mean score of patients' perceptions from the received hospital services in Iran

Table 3 shows the pooled estimation of the mean score of perceptions and expectations of patients in the six dimensions of service quality in Iranian hospitals. The random-effects meta-analysis indicated that the highest and lowest score of patients' perceptions were related to the responsiveness (4.06) and reliability (3.81) dimensions, respectively. The highest and lowest score of the patients' expectations were related to the tangibility (4.76) and access (4.51) dimensions, correspondingly. The systematic review showed that there were negative quality gaps in all six SERVQUAL dimensions. The gap score between the overall mean score of patients' expectations and perceptions was -0.90 . The highest and lowest quality scores were related to the reliability $(-0.88)$ and responsiveness $(-0.56)$ dimensions, respectively.

The Chi-squared based Q-test, I-squared, and Tausquared were used to check the heterogeneity among studies in the overall score of perceptions and expectations and in the perception and expectation scores of all six quality dimensions. The results did not indicate significant heterogeneity among the 13 articles $\left(\mathrm{I}^{2}\right.$ less than $20 \%$, Chi-squared based Q-test, 0.322, d.f. $=12$ [p>0.05] and

Table 3. The overall mean score of perceptions, expectations and the quality score gaps of hospital services for all the six SERVQUAL dimensions in Iran

\begin{tabular}{|c|c|c|c|}
\hline & $\begin{array}{c}\text { Perception } \\
(95 \% \text { confidence interval })\end{array}$ & $\begin{array}{c}\text { Expectation } \\
(95 \% \text { confidence interval }) \\
\end{array}$ & Gap \\
\hline Tangibility & $3.94(3.61-4.27)$ & $4.76(4.58-4.94)$ & -0.82 \\
\hline Reliability & $3.81(3.39-4.23)$ & $4.69(4.47-4.90)$ & -0.88 \\
\hline Responsiveness & $4.06(3.73-4.39)$ & $4.62(4.41-4.81)$ & -0.56 \\
\hline Assurance & $4.00(3.66-4.34)$ & $4.71(4.50-4.92)$ & -0.71 \\
\hline Empathy & $3.90(3.53-4.27)$ & $4.57(4.32-4.82)$ & -0.67 \\
\hline Access & $3.92(3.29-4.56)$ & $4.51(4.10-4.92)$ & -0.59 \\
\hline
\end{tabular}


Table 4. The Meta-regression analysis of the overall mean score of patients' perceptions from the services provided by Iranian hospitals

\begin{tabular}{|c|c|c|c|c|c|}
\hline & \multirow[t]{2}{*}{ Coefficient } & \multirow[t]{2}{*}{ Standard Error } & \multirow[t]{2}{*}{$\mathrm{p}$} & \multicolumn{2}{|c|}{$95 \% \mathrm{CI}$} \\
\hline & & & & Lower & Upper \\
\hline Publication year & -0.138 & 0.103 & 0.209 & -0.369 & 0.091 \\
\hline Sample size & -0.0005 & 0.0008 & 0.537 & -0.0024 & 0.001 \\
\hline Constant & 283.3 & 208.3 & 0.204 & -180.9 & 747.5 \\
\hline
\end{tabular}

Table 5. Egger's test for small-study effects to examine the publication bias for the overall mean score of perceptions and expectations

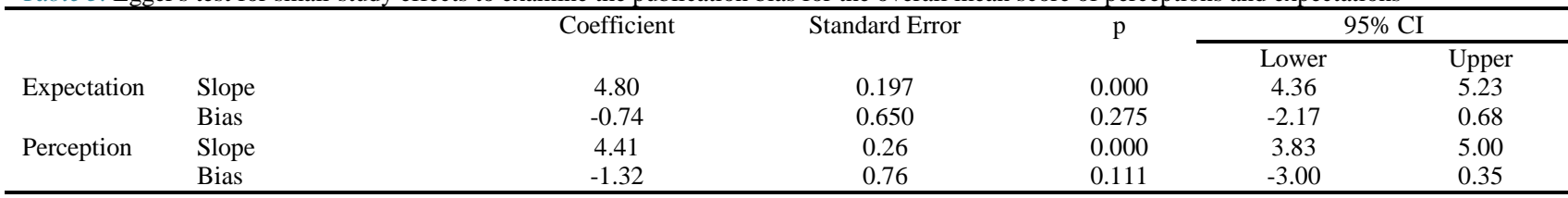

Note: Test of $\mathrm{H}_{0}$ : No small-study effects, P-value $=0.275$ for expectations and $\mathrm{P}$-value $=0.111$ for perceptions

$\left.\mathrm{Tau}^{2}<0.05\right)$ in all quality dimensions and in the overall mean score of expectations. The results, however, suggested statistically significant heterogeneity in the overall score of patients' perceptions among the 13 articles included in the study (Chi-squared based Q-test, 47.08, d.f. $=12 ; \mathrm{p}<0.0001$, I-squared statistics, $74.5 \%$ and Tausquared, 0.578).

The results of meta-regression (Table 4) indicated that the overall mean score of patients' perceptions was inversely related to sample size and year of publication, however, they were not statistically significant $(\mathrm{p}>0.05)$. The Egger's test for the overall mean score of patients' perceptions and expectations did not suggest any publication bias among the 13 studies included in the review (see Table 5).

\section{Discussion}

Improving service quality in healthcare is an important issue for patients, health professionals, and healthcare policy-makers both in developed and developing countries. This study, for the first time, aimed to systematically review the current literature on the quality of hospital service to provide a better understanding of service quality in Iranian hospitals. Based on the inclusion and exclusion criteria, 13 studies were selected to estimate the overall quality of services provided by hospitals in Iran. The meta-analysis indicated that the overall mean scores of patients' expectations and perceptions about the quality of hospital care in Iran were found to be 4.59 and 3.69, respectively. This indicated that the overall quality gap was negative (-0.9) and there is room for improvement in the quality of hospital services provided in Iranian hospitals. Significant differences between patients' expectations and perceptions were also found in a study by Bahadori et al. (32) in Tehran and Anbari and Tabaraie (33) in Arak, Iran. Similar results were also observed in India (34), Singapore (7) and Greece (35). Furthermore, the current review study suggested significant negative quality gaps in six SERVQUAL dimensions namely. tangibility, reliability, responsiveness, assurance, empathy, and access. This implies that the expectations of patients from hospital inpatient services were not met in Iranian hospitals across these dimensions. These results were consistent with the findings from national and international studies (7, 35-40). For example, a study conducted by Peprah and Atarah (18) indicated high negative quality gaps for all SERV-
QUAL dimensions in Ghanaian hospitals. A study in Cyprus also showed that patients' expectations from services were not met in public and private hospitals (35). Another study in national health service hospitals in North Greece also showed that negative quality gap exists between expectations and perceptions of service quality in the hospitals (41). Rohini and Mahadevappa (36) also found the negative service quality gap between patients' perceptions and their expectations from hospital services in Bangalore, India. A study in Singapour also indicated a significant differences in all SERVQUAL dimensions (7). Caha (42) also investigated the quality of services among private hospitals in Turkey and found significant differences between patients' expectations and perceptions in all the SERVQUAL dimensions.

The current review analysis indicated that negative gaps exist in all SERVQUAL dimensions of service quality in Iranian hospitals. Thus, quality improvements across all dimensions are required. The results of this systematic review indicated that reliability had the highest negative gap among all the six dimensions, whereas the lowest negative gap was related to responsiveness dimension. Reliability appears to require more focus as it was ranked highest gap, and patients lacked trust in services provided by hospitals. The gap in tangibility ranked the second negative gap, which may indicate that the resources were scarce or improperly utilized or maintained. Gaps in assurance ranked third in the quality gap, also needs attention for services to be convenient for patients and for staff to be more committed and sympathetic to patients' needs.

The results of this study were consistent with the findings other studies in Iran. A study by Gholami and Kavosi (13) in Nemazee Hospital, located in the south of Iran, also showed that the most negative quality gap was associated with the responsiveness dimension. Another study conducted in educational hospitals in Kermanshah city indicated that the least negative gap was associated with the responsiveness dimension (4). Mohebbifar et al. investigated service quality gap in teaching hospitals of Qazvin province in Iran and found that reliability and responsiveness were the two dimensions with the most and least quality score gaps, correspondingly (12). The latter study showed reducing waiting time to receive hospital care, providing hospital care in a timely and accurate manner and maintaining medical records appropriately may address the quality gaps in hospital care. These find- 
ings suggest that providers and healthcare workers in Iran should be aware of the medical and non-medical needs of patients in hospital settings and use patients' opinions for evaluation of the quality of care and improve patients' level of satisfaction on the quality of hospital services delivered at hospitals.

There is an imbalance between patients' need and the awareness of hospital care providers from patients' needs. This asymmetric information leads to the provision of low-quality services in hospitals $(44,45)$. Continuous monitoring of patients' expectations and perceptions is key to reducing this asymmetric information, which ultimately improves the quality of patient care $(46,47)$. Having detailed information about patients' service quality perceptions can help healthcare providers identify the dimensions and relevant items that affect the overall quality of services. The findings from this review highlighted relatively lower service quality in the reliability and tangibility dimensions in Iranian hospitals. This suggests that issues related to, for example, facilities and medical equipment, waiting time, the behavior of hospital staff to patients should be high-priority targets for quality improvement. It should be noted that sometimes, expectations of patients may be too high, unreasonably. Therefore, in these cases, expectations need to be adjusted.

Based on the results of this study, various policies (e.g., good responsiveness, access to health workers, and delivering healthcare in less time) can be implemented to improve the reliability dimension of hospital service quality in Iran. To improve the tangibility dimension of service quality, hospital managers should aim to provide hospital services using up-to-date equipment. Visually appealing physical facilities and well-dressed staff can also reduce the quality gap in tangibility dimension. It should be noted that the quality gap in one dimension has a spillover effect on other dimensions. Thus, an improvement in one dimension of the quality of services provided by hospitals leads to an increase in other quality dimensions.

The current review study has several limitations. Firstly, since Iranian scientific databases are relatively underdeveloped, some studies may have been missed in the review. Second, it was not possible to conduct separate systematic reviews based on hospital ownership status in Iran because of the small number of published articles in each category. Lastly, studies, the findings should be interpreted with caution due to the lack of studies that examined service quality for hospital services in some provinces of Iran.

\section{Conclusion}

The study demonstrated that expectations of patients from healthcare provided by Iranian hospitals have not been met and the expectations of patients were greater than their perceptions about the quality of services provided by Iranian hospitals. This suggests that healthcare providers in Iran should pay further attention to the patients' feedback and suggestions to improve the quality of inpatient services provided in Iranian hospital. Thus, effective customer service training programs that can help and equip hospital employees with vital customer service skills (e.g., conflict resolution, communication and handling difficult customers) and enhance them with the understanding of patients' expectations and emotional needs are recommended.

\section{Acknowledgment}

This work was supported by a research grant from Social Determinants of Health Research Center, Kurdistan University of Medical Sciences, Sanandaj, Iran (Grant Number IR.MUK.REC.1396/55).

\section{Conflict of Interests}

The authors declare that they have no competing interests.

\section{References}

1. Taner T, Antony J. Comparing public and private hospital care service quality in Turkey. Leadership in Health Services. 2006;19(2):1-10.

2. Sahney S, Banwet DK, Karunes S. An integrated framework of indices for quality management in education: a faculty perspective. TQM J. 2008;20(5):502-19.

3. Sabahi-Bidgoli M, Mousavi SGA, Kebriaei A, Seyyedi SH, Shahri S, Atharizadeh M. The quality of hospital services in Kashan educational hospitals during 2008-9: the patients' viewpoint. Feyz. 2011;15(2):146-52.

4. Rezaei S, Karami Matin B, Moradi K, Bijan B, Fallahi M, Shokati B, et al. Measurement of Quality of Educational Hospital Services by the SERVQUAL Model: The Iranian Patients' Perspective. Electron Physician. 2016;8(3):2101.

5. Ranjbar Ezatabadi M, Bahrami M, Zare Ahmadabadi H, Nasiri S, Arab M, Hadizadeh F, et al. Gap analysis between perceptions and expectations of service recipients through Servqual approach in Yazd, Afshar Hospital. Toloo-E-Behdasht. 2010;9(2):75-85.

6. Kiadaliri AA, Jafari M, Gerdtham U-G. Frontier-based techniques in measuring hospital efficiency in Iran: a systematic review and metaregression analysis. BMC Health Serv Res. 2013;13(1):312.

7. Cheng Lim P, Tang NK. A study of patients' expectations and satisfaction in Singapore hospitals. Int $\mathrm{J}$ Health Care Qual Assur. 2000;13(7):290-9.

8. Hjorth-Andersen C. The concept of quality and the efficiency of markets for consumer products. J Consum Res. 1984;11(2):708-18.

9. Ladhari R. Assessment of the psychometric properties of SERVQUAL in the Canadian banking industry. J Financ Serv. 2009;14(1):70-82.

10.Abolghasem Gorji H, Tabatabaei S, Akbari A, Sarkhosh S, Khorasan S. Using the service quality gap's model (SERVQUAL) in Imam Khomeini teaching hospital: 2012. J Health Adm. 2013;16(51):7-18.

11.Aghamolaei T, Eftekhaari TE, Rafati S, Kahnouji K, Ahangari S, Shahrzad ME, et al. Service quality assessment of a referral hospital in Southern Iran with SERVQUAL technique: patients' perspective. BMC Health Serv Res. 2014;14(1):322.

12.Mohebifar R, Barikani A, Hasani H. Measuring hospital Service Quality Gap from the viewpoint of inpatients in educational hospitals of Qazvin University of Medical Sciences (2012-13). Hospital. 2015;14(1):104-97

13. Gholami M, Kavosi Z. Services quality in emergency department of Nemazee Hospital: Using SERVQUAL model. J Health Manage Inform. 2016;3(4):120-6.

14.Karami Matin B, Rezaei S, Moradinazar M, Mahboubi M, Ataee M. Measurement of Quality of Primary Health Services by Servqual Model: Evidence from Urban Health Centers in West of Iran. Res J Med Sci. 2016;10(5):154-9.

15.Lee H, Delene LM, Bunda MA, Kim C. Methods of measuring health-care service quality. J Bus Res. 2000;48(3):233-46.

16.Sabahi-Bidgoli M, Mousavi SGA, Kebriaei A, Seyyedi SH, Shahri S, Atharizadeh M. The quality of hospital services in Kashan educational hospitals during 2008-9: the patients' viewpoint. Feyz. 2011;15(2):146-52

17.Parasuraman A, Zeithaml VA, Berry LL. Servqual: A multiple-item scale for measuring consumer perc. J Retail. 1988;64(1):12-40.

18.Peprah AA, Atarah BA. Assessing Patient's Satisfaction using 
SERVQUAL Model: A Case of Sunyani Regional Hospital, Ghana. Intl J Busi Soc Res. 2014;4(2):133-43.

19.Haghdoost AA, Moosazadeh M. The prevalence of cigarette smoking among students of Iranâ€ $€^{\mathrm{TM}} \mathrm{S}$ universities: A systematic review and meta-analysis. J Res Med Sci. 2013;18(8):717-25.

20.Moosazadeh M, Nekoei-moghadam M, Emrani Z, Amiresmaili M. Prevalence of unwanted pregnancy in Iran: a systematic review and meta-analysis. Int J Health Plann Manage. 2014;29(3):277-90.

21.Rezaei S, Hajizadeh M, Zandian H, Fathi A, Nouri B. Period Prevalence and Reporting Rate of Needlestick Injuries to Nurses in Iran: A Systematic Review and Meta-Analysis. Res Nurs Health. 2017;40(4): 311-22.

22.Ameryoun A, Dopeykar N, Nasiri T, Meskarpour Amiri M, Gholami- Fesharaki M, Karamali M. Assessment the Gap between Patients' Expectations and the Services Provided to them in Selected Hospitals of Tehran in 2012. J Police Med. 2013;2(1):1-10.

23.Sina K, Babai Shibabandani M, Nadi Ghara A. Factors Influencing the Inpatients' Satisfaction Based on the SERVQUAL Model. J Mazandaran Univ Med Sci. 2015;24(121):299-308.

24.Hekmatpou D, Sorani M, Farazi AA, Fallahi Z, Lashgarara B. A survey on the quality of medical services in teaching hospitals of Arak University of Medical Sciences with SERVQUL model in Arak, 2010. J Arak Uni Med Sci. 2012;15(7):1-9.

25.Bahmei J, Rahimi H, Rahgoshay I, Kavosi Z. Quality Evaluation of Emergency Department Services of Nemazee Hospital from the Patients' Viewpoint. Depiction of Health. 2016;7(1):18-26.

26.Razlansari M, Teimouri B, Alipour Shirsavar H, Taleghani M, Ashtarian H. Patients' views on perceived services quality using SERVQUAL Model at educational and medical centers of Kermanshah University of Medical Sciences 2013. J Clin Res Param Sci. 2012;1(3):7484.

27.Ajam M, Sadeghifar J, Anjomshoa M, Mahmoudi S, Honarvar H, Mousavi SM. Assessing quality of healthcare service by the SERVQUAL model: A case study of a field hospital. Journal Mil Med. 2014;15(4):273-9.

28.Ayoubian A, Dopeykar N, Mehdizadeh P, Hoseinpourfard M, Izadi M. Surveying the Quality of care services in a military health center according to the SERVQUAL model. Journal Mil Med. $2015 ; 16(4): 225-9$.

29.Gholami M, Jabbari A, Kavosi Z, Chamanpara P. An Assessment of the Attitudes of Medical Tourists toward the Quality of the Services Delivered by Hospitals in Shiraz, Iran, Using the SERVQUAL Model. Health Inf Manage. 2016;13(2):145-52.

30.Sadeghdaghighi M, Chegini MG. Analysis of Services Quality on Customer's Satisfaction Using SERVQUAL Model. J Engin Tech. 2016;5(1):49-71.

31.Zarei E, Tabatabai G, Mahmud S, Rahimi Forushani A, Rashidiyan A, Arab M. Hospital Services Quality From Patients' Point Of View: A Cross-Sectional Study In Tehran Private Hospitals. Payavard. 2011;5(4):66-76.

32.Bahadori M, Zaboli R, Ghanbari A. Quality of services provided to veterans referred to a branch of the armed forces in Hamadan. IJWPH. 2013;6(1):44-50.

33.Anbari Z, Tabaraie Y. Measurement of quality of hospital services via SERVQUAL Model. Bull Env Pharmacol Life Sci. 2013;3(1):51-6.

34.Brahmbhatt M, Baser N, Joshi N. Adapting the SERVQUAL scale to hospital services: An empirical investigation of patients' perceptions of service quality. Int J Multidiscip Res. 2011;1(8):27-42.

35.Arasli H, Haktan Ekiz E, Turan Katircioglu S. Gearing service quality into public and private hospitals in small islands: empirical evidence from Cyprus. Int J Health Care Qual Assur. 2008;21(1):8-23.

36.Rohini R, Mahadevappa B. Service quality in Bangalore hospitals-an empirical study. J Serv Res. 2006;6(1):59-84.

37.Bakar C, Seval Akgün H, Al Assaf A. The role of expectations in patient assessments of hospital care: an example from a university hospital network, Turkey. Int $\mathbf{J}$ Health Care Qual Assur. 2008;21(4):343-55.

38.Mi Dahlgaard-Park S, Karassavidou E, Glaveli N, Papadopoulos CT. Quality in NHS hospitals: no one knows better than patients. Mea Busi Exce. 2009;13(1):34-46.

39.Butt MM, de Run CE. Private healthcare quality: applying a SERVQUAL model. Int J Health Care Qual Assur. 2010;23(7):658-73.

40.Mohebifar R, Hasani H, Barikani A, Rafiei S. Evaluating Service Quality from Patients' Perceptions: Application of Importanceperformance Analysis Method. Osong Public Health Res Perspect.
2016;7(4):233-8.

41.Karassavidou E, Glaveli N, Papadopoulos CT, eds. Health Care Quality in Greek NHS Hospitals: No one knows better than patients. 11th QMOD Conference Quality Management and Organizational Development Attaining Sustainability From Organizational Excellence to SustainAble Excellence; 20-22 August; 2008 in Helsingborg; Sweden; 2008: Linköping University Electronic Press.

42. Çaha H. Service quality in private hospitals in Turkey. J Econ Sci Res. 2007;9(1):55-69.

43.Li M, Lowrie DB, Huang CY, Lu XC, Zhu YC, Wu XH, et al. Evaluating patients' perception of service quality at hospitals in nine Chinese cities by use of the ServQual scale. Asian Pac J Trop Biomed. 2015;5(6):497-504.

44.Zarei A, Arab M, Froushani AR, Rashidian A, Tabatabaei SMG. Service quality of private hospitals: The Iranian Patients' perspective. BMC Health Ser Res. 2012;12(1):31.

45.Donnelly M, Wisniewski M, Dalrymple JF, Curry AC. Measuring service quality in local government: the SERVQUAL approach. Int J Pub Sec Manag. 1995;8(7):15-20.

46.Sharma B, Gadenne D. An investigation of the perceived importance and effectiveness of quality management approaches. TQM Maga. 2001;13(6):433-45.

47.West E. Management matters: the link between hospital organization and quality of patient care. Qual Saf Health Care. 2001;10(1):40-8. 